\title{
A national survey of availability of key essential medicines for children in Sri Lanka
}

\author{
R Balasubramaniam ${ }^{1}$, B V S H Beneragama², S Sri Ranganathan ${ }^{1}$ \\ (Index words: access to medicines, essential medicines, paediatric medicines, availability, children)
}

\begin{abstract}
Objectives To investigate the availability of key essential medicines for children in Sri Lanka.

Methods This national survey assessed the availability of 25 key essential medicines for children using the WHO/Health Action International medicine price methodology. Data were collected from a representative sample of 40 public hospitals (Outpatients Department pharmacies), 40 private and 8 'Rajya Osusala' (ROS) pharmacies. The hospitals and pharmacies were selected from 8 provinces using a multistage clustered approach to represent different levels of public hospitals. Descriptive statistics were used for analysis.

Results The mean per cent availability of the basket of survey medicines was $52 \%$ in pubic hospitals when compared to $80 \%$ in private, and $88 \%$ in ROS pharmacies. teaching/general hospitals had better availability (mean per cent availability $62 \%$ ) than district hospitals (54\%), peripheral units (49\%) and central dispensaries (45\%). Availability of anti-infectives, anti-asthma medicines and oral liquid preparations of carbamazepine, iron, paracetamol, domperidone and ibuprofen was found to be less in public hospitals than private and ROS pharmacies. Availability in public hospitals similar to that of private and ROS pharmacies was only for paracetamol tablet, oral rehydration salt, vitamin $\mathrm{C}$ and chlorphenamine syrup.

Conclusions Key essential medicines for children were less available in public hospitals than in private and ROS pharmacies. This deprives children from access to effective and safe medicines more in the public hospitals than in the private sector or ROS.
\end{abstract}

Ceylon Medical Journal 2011; 56: 101-107

\section{Introduction}

Essential medicines are those that satisfy the priority healthcare needs of the population. They should be available within the context of functioning health systems at all times in adequate amounts in the appropriate dosage forms [1]. The fourth revision of Essential Medicine List (EML) for Sri Lanka was published in 2009 [2].
The first WHO Essential Medicines List for children (EMLc) was developed only in 2007, and it has been updated once in 2009 [3]. In Sri Lanka there is no EMLc, but the main EML includes paediatric dosage forms and strengths.

The object of having an EML is to ensure sustained availability of the listed medicines. However, many developing countries have not achieved this despite having an EML as a document. Availability (physical access), affordability (economic access) and acceptability (socio-cultural access) are determinants of universal access, defined as having medicines continuously available and affordable at public or private medicine outlets that are within one hour's walk from the homes of the population [4].

It has been estimated that one third of the world's population does not have regular access to essential medicines [5]. The access to essential medicines for children has not been studied widely. One survey done in the capital cities of 14 countries in Central Africa concluded that the availability of key essential medicines for children was poor [6].

Our study examined the physical access (availability) to key essential medicines for children. This has not been previously studied in Sri Lanka, either in adults or in children though Sri Lanka is a pioneer of the essential medicine concept.

We have investigated the availability of key essential medicines used for common childhood diseases in public hospitals, private and 'Rajya Osusala' (ROS) pharmacies in Sri Lanka using the WHO and Health Action International (HAI) medicine price methodology [7]. To our knowledge, this is the first such country survey reported.

\section{Methods}

Survey design and setting The methodology of this survey was adapted from WHO/HAI medicine price methodology (7). This was a cross-sectional descriptive country survey, and data were collected in mid 2009 from Outpatient

${ }^{1}$ Department of Pharmacology, Faculty of Medicine, University of Colombo, Sri Lanka, ${ }^{2}$ Division of Medical Supplies and Technology, Ministry of Healthcare and Nutrition, Sri Lanka.

Correspondence: SSR, e-mail: <sshalini14@hotmail.com>. Received 10 January 2011 and revised version accepted 25 April 2011. Competing interests: none declared. 
department (OPD) pharmacies of a large number of public hospitals, and from private and ROS pharmacies situated in all provinces except the Northern Province.

Survey areas (Sample Unit) For a country survey, it is recommended to include the country's major urban centre (usually the capital city), and 5 other survey areas randomly chosen from all the administrative areas that can be reached within 1 day from the major urban centre using transportation, usually car, bus or train [7]. Because health comes under the purview of provincial councils in Sri Lanka, we chose the province as the sample unit. Northern Province was excluded as it was not reachable then within one day from Colombo, and some districts were inaccessible due to the civil war.

Selecting the sample Multistage cluster sampling approach was used. For convenience, public hospitals were used to anchor the sample, with ROS and private pharmacies chosen by their proximity to public hospitals. In each survey area (province), the main public hospital (Teaching (TH)/General Hospital (GH)) was first chosen.
A list of public hospitals that have OPD pharmacies or dispensaries that are within 3 hours' travel from the chosen $\mathrm{TH} / \mathrm{GH}$ was made for each survey area, and considering the Sri Lankan healthcare system, using a multistage cluster sampling approach, we selected one district hospital (DH), one peripheral unit (PU) and two central dispensaries (CD) for each province in addition to its main TH/GH. In addition, for each province, the ROS pharmacy that is closest to its main $\mathrm{TH} / \mathrm{GH}(\mathrm{n}=1)$ and one private pharmacy that is closest to each public hospital $(n=5)$ were selected.

Our sampling approach led to the selection of 88 survey samples from the 8 survey areas (provinces) as follows: 5 public hospitals ( 1 - TH/GH, 1- DH, 1- PU and 2 - CDs), 5 private pharmacies (that is closest to each public hospital) and 1 ROS pharmacy for each province.

Selection of survey medicines Having perused references 2, 3, 6 and 7 we selected 25 key essential medicines for children of a specific dosage form and strength (Table 1). The number was limited to 25 considering the logistics of data collection.

Table 1. Surveyed medicines

\begin{tabular}{|c|c|}
\hline Medicine & Dosage form and strength \\
\hline Amoxicillin & Suspension $125 \mathrm{mg} / 5 \mathrm{ml}(100 \mathrm{ml})$ \\
\hline Amoxicillin & $250 \mathrm{mg}$ (capsule/tablet) \\
\hline Amoxicillin + clavulanic acid & Suspension $125 \mathrm{mg}+31.25 \mathrm{mg} / 5 \mathrm{ml}(100 \mathrm{ml})$ \\
\hline Beclometasone-MDI & Inhaler 50 microgram/dose (200 doses) \\
\hline Carbamazepine & Suspension $100 \mathrm{mg} / 5 \mathrm{ml}(100 \mathrm{ml})$ \\
\hline Ceftriaxone* & Injection 1 gram (vial) \\
\hline Chlorphenamine & Syrup $2 \mathrm{mg} / 5 \mathrm{ml}(100 \mathrm{ml})$ \\
\hline Clotrimazole & Topical cream $1 \%$ (15 g tube) \\
\hline Cloxacillin & Syrup $125 \mathrm{mg} / 5 \mathrm{ml}(100 \mathrm{ml})$ \\
\hline Co-trimoxazole & Suspension $200 \mathrm{mg}+40 \mathrm{mg} / 5 \mathrm{ml}(100 \mathrm{ml})$ \\
\hline Diazepam* & Injection $5 \mathrm{mg} / \mathrm{ml}(2 \mathrm{ml}$ ampoule $)$ \\
\hline Diethylcarbamazine citrate & $50 \mathrm{mg}$ (tablet) \\
\hline Domperidone & Syrup 5 mg / 5ml (100 ml) \\
\hline Erythromycin & Syrup 125 mg / 5 ml (100 ml) \\
\hline Ferrous salt & Suspension $30 \mathrm{mg} / \mathrm{ml}(250 \mathrm{ml})$ \\
\hline Ibuprofen & Syrup $100 \mathrm{mg} / 5 \mathrm{ml}(100 \mathrm{ml})$ \\
\hline Mebendazole & Chewable tablet $100 \mathrm{mg}$ ( 6 tablets) \\
\hline Mebendazole & Syrup $100 \mathrm{mg} / 5 \mathrm{ml}(30 \mathrm{ml})$ \\
\hline Metronidazole & $200 \mathrm{mg}$ (tablet) \\
\hline Oral rehydration salt & Packet to make 1 litre of solution \\
\hline Paracetamol & Syrup 120 mg / 5 ml (100 ml) \\
\hline Paracetamol & $500 \mathrm{mg}$ (tablet) \\
\hline Salbutamol-MDI & Inhaler 100 microgram / dose (200 doses) \\
\hline Salbutamol & Respiratory solution $0.5 \%(10 \mathrm{ml})$ \\
\hline Vitamin C & $100 \mathrm{mg}$ (tablet) \\
\hline
\end{tabular}

\footnotetext{
* Excluded from analysis
} 
Data collection We designed a user-friendly data collection instrument titled "paediatric essential medicines availability and price data collection form". To strengthen the authenticity and uniformity of data, two principal investigators (RB, SSR) personally collected the data from survey samples. The results were validated by repeating the survey on the same day at one public hospital and one private pharmacy in every survey area and comparing the result to the first data collection.

All appropriate precautions were taken to ensure correct entry of data. Availability was analysed for the individual survey sample examining the percentage availability of the basket of survey medicines (reported as per cent availability for each survey sample), as well as for individual medicines by examining its percentage availability in the survey settings (reported as percentage of medicine outlets which had the survey medicine on the day of survey).

A few survey medicines were excluded from analysis for some levels of public hospitals as they are not expected to be available in them [1]. Injections of diazepam and ceftriaxone were excluded from public hospital analysis as injections are generally not issued to OPD pharmacies,
[2] salbutamol and beclometasone inhaler and carbamazepine syrup were not analysed for DHs, PUs and CDs as they are not issued to these hospitals, and [3] salbutamol respiratory solution was not analysed for $\mathrm{TH} /$ $\mathrm{GH}$ since it is directly issued to the Emergency Units.

The study was approved by the Ethics Review Committee, Faculty of Medicine, Colombo. Permission was also obtained from all the relevant authorities before data collection.

\section{Results}

\section{Availability of the basket of key essential medicines for children}

Inter-sector analysis mean per cent availability of survey medicines was $52 \%$ (range $=25-75, \mathrm{SD}=13.9)$ in public hospitals compared to $80 \%$ (range $=56-96$, $\mathrm{SD}=11)$ in private, and $88 \%($ range $=76-100, \mathrm{SD}=9.5)$ in ROS pharmacies (Table 2). None of the public hospitals had "high" ( $>80 \%)$ availability when compared to $50 \%$ of private and $62.5 \%$ of ROS pharmacies; $37.5 \%$ of public hospitals had "low" (30-49\%) or "very low" (<30\%)" availability, and none of the private or ROS pharmacies had "low" or "very low" availability.

\section{Table 2. Per cent availability of survey medicines in public hospitals, private and 'Rajya Osusala' pharmacies}

\begin{tabular}{|c|c|c|c|c|c|c|c|c|c|}
\hline \multirow[b]{2}{*}{ Public Hospitals } & \multicolumn{9}{|c|}{ Per cent availability of key paediatric essential medicines (\%) } \\
\hline & $1 *$ & 2 & 3 & 4 & 5 & 6 & 7 & 8 & Mean (SD) \\
\hline $\mathrm{TH}$ & 61 & 48 & 61 & 57 & 65 & 57 & 74 & 74 & $62(8.8)$ \\
\hline $\mathrm{DH}$ & 50 & 60 & 70 & 75 & 55 & 45 & 50 & 25 & $54(15.5)$ \\
\hline PU & 40 & 50 & 60 & 65 & 60 & 30 & 35 & 55 & $49(13)$ \\
\hline CD1 & 30 & 45 & 40 & 25 & 65 & 45 & 40 & 55 & $45(13)$ \\
\hline $\mathrm{CD} 2$ & 25 & 60 & 50 & 65 & 55 & 40 & 40 & 80 ** & \\
\hline \multicolumn{10}{|l|}{ Private pharmacies } \\
\hline $\mathrm{TH}-\mathrm{PP}$ & 88 & 80 & 96 & 88 & 80 & 88 & 88 & 92 & $87.5(5.4)$ \\
\hline DH - PP & 56 & 56 & 80 & 92 & 76 & 84 & 88 & 76 & $76(13.5)$ \\
\hline PU - PP & 68 & 80 & 84 & 80 & 96 & 80 & 84 & 76 & $81(8.9)$ \\
\hline CD1 - PP & 96 & 68 & 60 & 80 & 60 & 84 & 88 & 88 & $78.75(11.7)$ \\
\hline CD2 - PP & 68 & 84 & 92 & 76 & 84 & 88 & 80 & 64 & \\
\hline ROS pharmacies TH-ROS & 96 & 92 & 100 & 76 & 88 & 76 & 96 & 80 & $88(9.5)$ \\
\hline
\end{tabular}

1. Public hospitals: 40 public hospitals from 8 Provinces; $T H-1, D H-1, P U-1, C D-2$ per each Province.

2. Private pharmacies: 40 private pharmacies in 8 Provinces; TH-PP - 1, DH-PP - 1, PU-PP - 1, CD-PP - 2 per each Province.

3. ROS pharmacies: 8 ROS pharmacies in 8 Provinces (closest to TH/GH); 1 per each Province.

4. *: Number 1, 2, 3... in the row title indicates different Provinces.

5. TH= teaching hospital, TH-PP = private pharmacy closest to $T H, D H=$ district hospital, DH-PP= private pharmacy closest todistrict hospital, $P U=$ peripheral unit, $P U-P P=$ private pharmacy closest to peripheral unit, $C D=c e n t r a l$ dispensary, $C D-P P=$ private pharmacy closest to $C D$.

6. **Note: The availability data in CD2 of the Province 8 cannot be compared with other hospitals as this particular CD is still getting its medicine supplies from a Non-Governmental Organization even months after civil war and re-settlement. It was excluded in the calculation of mean per cent availability. 
Within-sector analysis In the public sector, $\mathrm{TH} / \mathrm{GH}$ (range: $48-74 \%$, mean: $62 \%$ ) had slightly better availability than the DHs (range: $25-75 \%$, mean 54\%), PUs (range: $30-65 \%$, mean $49 \%$ ) and CDs (range: $25-65 \%$, mean $45 \%$ ) (Table 2). A similar pattern was noted in the private sector as well with private pharmacies closest to TH/GHs had slightly better availability than the private pharmacies closest to DHs (PP-DH), PUs (PP-PU) and CDs (PP-CDs) (Table 2).

In the public sector, there was no relationship between the percent availability of survey medicines and distance of the hospitals from Colombo for any level of hospital. For example, the percent availability in many hospitals located far away from Colombo was either equal or more than in the hospitals that were close to Colombo. Similar observations were seen with private pharmacies as well.

\section{Availability of individual key essential medicines for children}

The results are reported as percentage of medicine outlets which had the survey medicine on the day of survey. The survey medicines are grouped into [1] antiinfective agents (Table 3), [2] drugs used in the treatment of bronchial asthma (Figure 1), [3] oral liquid dosage forms of carbamazepine, iron, paracetamol, domperidone and ibuprofen (Table 4), and [4] rest of the survey medicines (Figure 2).

Table 3. Availability of key essential anti-infective agents for children: inter-sector comparison

\begin{tabular}{lcccccc}
\hline Medicine & \multicolumn{2}{c}{ Public } & $(n=40)$ & \multicolumn{2}{c}{ Private $(n=40)$} & \multicolumn{2}{c}{ ROS (n=8) } \\
& No & $\%$ & No & $\%$ & No & $\%$ \\
\hline Amoxicillin suspension & 18 & 45 & 40 & 100 & 8 & 100 \\
Amoxicillin capsule/tablet & 36 & 90 & 40 & 100 & 8 & 100 \\
Amoxicillin + clavulanic acid suspension & 05 & 12.5 & 39 & 98 & 8 & 100 \\
Clotrimazole topical & 11 & 27.5 & 40 & 100 & 8 & 100 \\
Cloxacillin syrup & 27 & 67.5 & 37 & 93 & 8 & 100 \\
Co-trimoxazole suspension & 2 & 5 & 27 & 68 & 7 & 87.5 \\
Diethylcarbamazine citrate tablet & 22 & 55 & 32 & 80 & 8 & 100 \\
Erythromycin syrup & 21 & 52.5 & 36 & 90 & 8 & 100 \\
Mebendazole chewable tablet & 38 & 95 & 37 & 93 & 8 & 100 \\
Mebendazole syrup & 2 & 5 & 14 & 35 & 3 & 37.5 \\
Metronidazole tablet & 35 & 87.5 & 38 & 95 & 8 & 100 \\
\hline
\end{tabular}

Table 4. Availability of oral liquid dosage forms of some key essential medicines for children: inter-sector comparison

\begin{tabular}{|c|c|c|c|c|c|c|}
\hline \multirow[t]{2}{*}{ Medicine name } & \multicolumn{2}{|c|}{ Public $(n=40) *$} & \multicolumn{2}{|c|}{ Private $(n=40)$} & \multicolumn{2}{|c|}{$\operatorname{ROS}(n=8)$} \\
\hline & No & $\%$ & No & $\%$ & No & $\%$ \\
\hline Carbamazepine suspension & 0 & 0 & 17 & 42.5 & 5 & 62.5 \\
\hline Ferrous suspension & 5 & 12.5 & 29 & 73 & 6 & 75 \\
\hline Domperidone syrup & 19 & 47.5 & 38 & 95 & 8 & 100 \\
\hline Ibuprofen syrup & 8 & 20 & 36 & 90 & 5 & 62.5 \\
\hline Paracetamol syrup & 26 & 65 & 38 & 95 & 8 & 100 \\
\hline
\end{tabular}

*For carbamazepine suspension: in the public sector, only $\mathrm{TH} / \mathrm{GH}(n=8)$ were included for analysis. 
Figure 1. Availability of essential anti-asthma medicines for children: inter sector comparison

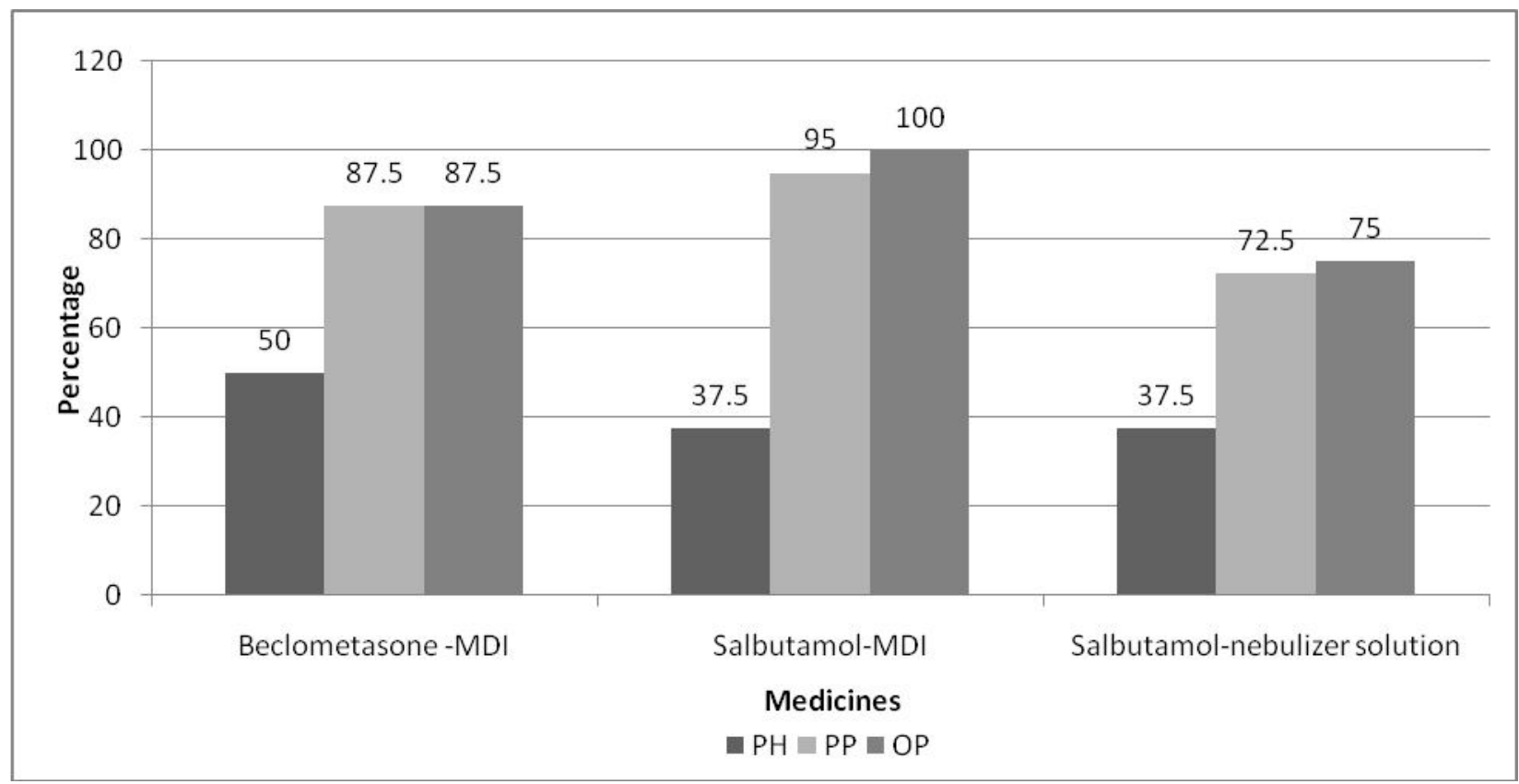

1. In public sector, TH/GH was excluded from the analysis for salbutamol - nebulizer solution $(n=32)$. Metered dose inhalers (MDI) of salbutamol and beclometasone was analysed only for $T H / G H(n=8)$.

2. $P H=$ Public hospitals, $P P=$ Private pharmacies, $O P=$ Rajya Osusala pharmacies.

Figure 2. Availability of paracetamol tablet, ORS, vitamin C and chlorphenamine syrup: inter sector comparison

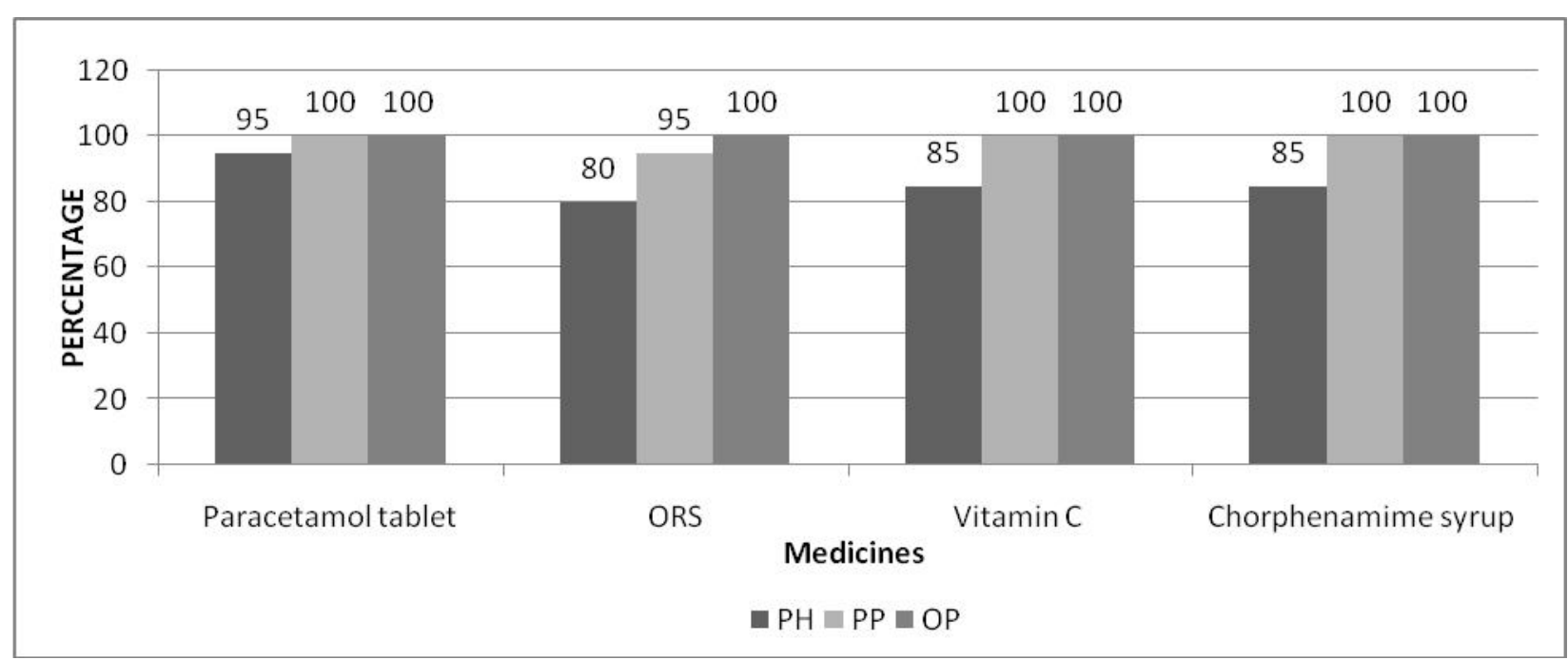

1. $P H=$ Public hospitals, $P P=$ Private pharmacies, $O P=$ Rajya Osusala pharmacies

Eleven of the survey medicines were commonly used anti-infectives. Their availability was less in public hospitals than in private and ROS pharmacies (Table 3). For example amoxicillin suspension was available in $45 \%$ of the public hospitals compared to $100 \%$ of private and ROS pharmacies. Availability in public hospitals was com- parable to private and ROS pharmacies for oral solid dosage forms of amoxicillin, metronidazole and mebendazole. The availability of anti-infectives was good in ROS pharmacies: except for cotrimoxazole suspension (available in 87.5\%), and mebendazole syrup (available in $37.5 \%$ ), the other 9 antiinfective agents were available in all the ROS pharmacies. 
Availability of oral liquid dosage forms of commonly needed essential antibacterial agents in the OPDs such as amoxicillin, and erythromycin in $\mathrm{TH} / \mathrm{GHs}$ was $50 \%$ and $62.5 \%$; in DHs $37.5 \%$ and $75 \%$, in PUs $50 \%$ and $50 \%$; and in CDs $43.5 \%$ and $37.5 \%$. Within the public hospitals, availability of anti-infectives was slightly better in TH/GH compared to DH, PU and CD. This was observed in the private sector as well with slightly better availability in private pharmacies closest to $\mathrm{TH} / \mathrm{GH}$ than the private pharmacies closest to other levels of public hospitals. Within the public hospitals, availability in CDs as good as that of DHs, and PUs was observed for many antiinfectives, which too was observed in the private pharmacies with no or minimal variation in the availability among the private pharmacies closest to DHs, PUs, and CDs.

Table 4 shows the availability data of oral liquid dosage forms of 5 key essential medicines for children. In the public sector, carbamazepine was analysed only for $\mathrm{TH} / \mathrm{GH}(\mathrm{n}=8)$ whereas the other 4 were analysed for all 40 public hospitals. As for anti-infective agents, poor availability of these medicines was observed in the public hospitals with none of the TH/GH having the oral liquid dosage form of carbamazepine. Availability of these 5 medicines in ROS pharmacies was superior to other two sectors. Paracetamol syrup was available in $65 \%$ of public hospitals compared to $95 \%$ of private and $100 \%$ of ROS pharmacies. In the public sector, availability in CDs as good as that of DHs, and PUs was observed for liquid dosage forms of paracetamol and iron.

Availability of drugs used in the treatment of bronchial asthma in the private and ROS pharmacies was superior to public hospitals (Figure 1). Salbutamol respiratory solution was available in $37.5 \%, 50 \%$ and $31.25 \%$ of DHs, PUs and CDs, compared to $62.5 \%, 75 \%$ and $62.5 \%$ of PP-DHs, PP-PUs and PP-CDs.

Rest of the survey medicines comprised paracetamol tablet, oral rehydration salt, chlorphenamine syrup and vitamin $C$, and their availability in public hospitals was as good as that of private and ROS pharmacies (Figure 2).

\section{Discussion}

Our study has gathered national data on availability of key essential medicines for children. The significant strengths of the study are that it was conducted in all accessible provinces of Sri Lanka within a short period, using internationally accepted data collection methods that permit regional and global comparisons [6]. The limitation of the study is that the availability data only refer to availability of a given medicine in a particular dosage form and strength on the day of data collection at each outlet. This may not necessarily reflect average monthly or yearly availability of medicines at these outlets. However, the methodology has been accepted by Health Action International and $\mathrm{WHO}$ as a practical data collection tool to assess availability and cost of medicines $[6,8,9]$.

The selection of the survey medicines needs no special justification. All were in the 2006 EML, although vitamin $\mathrm{C}$ and mebendazole syrup were deleted in 2009. It is the responsibility of a satisfactorily functioning healthcare system to make medicines available. In Sri Lanka, healthcare is provided free at the point of delivery in the public sector. Ideally, the expected mean per cent availability of these key essential medicines should be at least $80 \%$ in public hospitals. But we found that the actual situation was far from the ideal with an overall mean per cent availability of $52 \%(\mathrm{TH}-62 \%, \mathrm{DH}-54 \%$, PU $-49 \%$, $\mathrm{CD}-45 \%)$. It is clear that remedial action is urgently needed.

A survey that assessed the availability of essential medicines for children in the capital city of 14 central African countries also using a similar methodology reported poor availability of essential medicines for children [6]. This survey covered 17 medicines in 20 dosage forms suitable for children. The results showed that the availability of survey medicines was $15-75 \%$ in the central medical stores, $15-70 \%$ in the teaching hospitals, $10-80 \%$ in the district hospitals, $18-48 \%$ in primary health care clinics and $38-62 \%$ in the retail or private pharmacies [6].

The other major deficiency in the public hospitals in Sri Lanka was poor availability of oral liquid and inhaled dosage forms of key essential medicines for children. When a medicine is not available in a suitable oral paediatric dosage form, the practice is to break the adult dosage forms and dissolve fractions in various liquids. Bioavailability of such manipulated adult dosage forms is unproven and its palatability is uncertain. They are likely to result in treatment failure, especially of diseases such as epilepsy that require a consistent steady state plasma concentration for effective control. Our survey found that none of the TH/GH surveyed had liquid formulation of carbamazepine.

In contrast to the public sector, availability of a medicine in the private sector is mainly determined by demand, popularity, moving rate and profitability. Since all survey medicines are commonly used essential medicines for children in the community setting, it explains their good mean per cent availability in the ROS and private pharmacies. One exception was mebendazole syrup, but this may not be a fast moving product as the mebendazole tablets are chewable and syrup is often redundant.

Overall, the availability of survey medicines tends to be better in ROS than in private pharmacies. However, ROS pharmacies are few and not evenly distributed.

Access to essential medicines for children is globally accepted now as an important contributing factor for good childhood health outcome. The World Health Assembly Resolution WHA60.20 (2007) encourages its 193 member 
states, including Sri Lanka, to promote access to essential medicines for children [10].

In conclusion, the availability of key essential medicines for children was low in public hospitals. This deprives the children who attend the public hospitals from access to effective and safe medicines. Sri Lanka needs to adopt the four-part framework formulated by the WHO such as rational selection and use of essential medicines, affordable prices, sustainable financing and reliable supply systems to improve the access to key essential medicines for children [11].

\section{Acknowledgments}

We acknowledge the WHO/Sri Lanka and South East Asian Regional Office (SEARO) for funding (SE SRL DDE RB 08 17.1.1), Drs. S A C Senadeera and R Thanikaivasan for assisting in data entry, Ms. Priyani Perera and Ms. Inoka Gammune of the Department of Pharmacology, Faculty of Medicine, Colombo for secretarial assistance.

\section{References}

1. World Health Organization. The selection of essential drugs. Report of the WHO Expert Committee. Technical Report Series No 615. Geneva: WHO; 1977.

2. Ministry of Healthcare and Nutrition and Department of Pharmacology, Faculty of Medicine, University of Colombo. National List of Essential Medicines, Sri Lanka, 4th revision. 2009.

3. World Health Organization. The selection and use of essential medicines. Report of the WHO Expert Committee, March 2009 (including the 2nd Model List of Essential Medicines for Children). Geneva: WHO; 2009.

4. United Nations Development Group. Indicators for Monitoring the Millennium Development Goals. United Nations: New York, 2003.

5. Quick JD. Essential medicines twenty five years on. Closing the access gap. Health Policy Plan 2003; 18: 1-3.

6. Robertson J, Forte G, Trapsida JM, Hill S. What essential medicines for children are on the shelf? Bulletin of the World Health Organisation 2009; 87: 231-7.

7. Health Action International and World Health Organization. Medicine prices, availability, affordability and price components, 2008. Available from http://www.haiweb.org/ medicineprices/ (accessed on 8th January 2009).

8. Cameron A, Ewen M, Ross-Degnan D, Ball D, Laing R. Medicine prices, availability, and affordability in 36 developing and middle-income countries: a secondary analysis. www.thelancet.com. Published online December 1, 2008 DOI:10.1016/S0140- 6736(08)61762-6 1

9. Mendis S, Fukino K, Cameron A, Laing R, Filipe A, Khatib $\mathrm{O}$, Leowski J, Ewen M. The availability and affordability of selected essential medicines for chronic diseases in six lowand middle-income countries. Bulletin of the World Health Organisation 2007; 85: 279-88.

10. Sixtieth World Health Assembly. 5. Resolution WHA60.20. Better medicines for children. Available from: http:// www.who.int/gb/ebwha/pdf_files/ WHA60/A60_R20en.pdf [accessed on 2 April 2010].

11. World Health Organization. Equitable access to essential medicines: a framework for collective action. Policy perspectives on medicines, No 8. Geneva: WHO; 2004. 